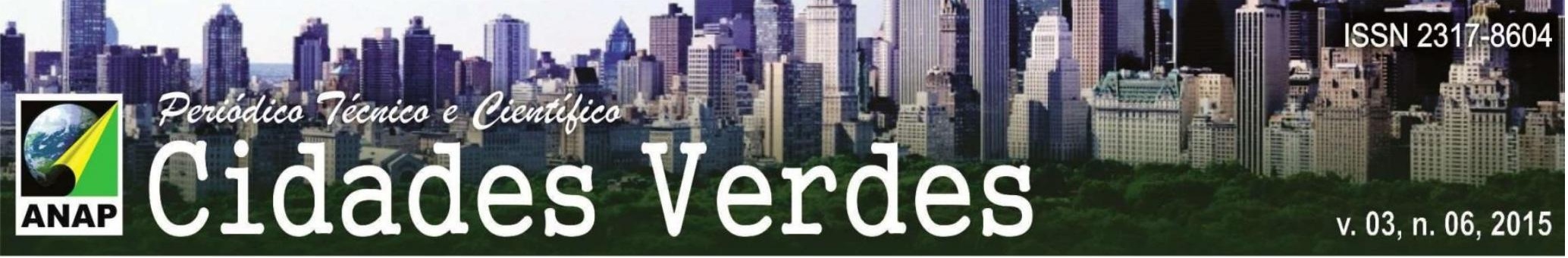

Titulo do Trabalho

\title{
ESPÉCIES EXÓTICAS NA ARBORIZAÇÃO VIÁRIA DO MUNICÍPIO DE RANCHARIA - SP
}

Nome do Autor (a) Principal

Lucilene de Brito

Nome (s) do Coautor (a) (s)

Silvério Takao Hossomi

Nome (s) do Orientador (a) (s)

Luiz Waldemar de Oliveira

Instituição ou Empresa

UNOESTE - Universidade Unoeste Paulista - Presidente Prudente-SP

Instituição (s) de Fomento

E-mail de contato

luavalon@hotmail.com; veira@unoeste.br

Palavras-chave

Espécies exóticas. Arborização homogênea. Licania tomentosa.

INTRODUÇÃO

A arborização urbana pode promover e preservar a biodiversidade, sendo sítio de reprodução para várias espécies de animais (ALVEY, 2006). Portanto, a paisagem vegetal tem papel importante no equilíbrio na composição da avifauna urbana (ARGEL-DE-OLIVEIRA, 1996), pois as árvores em zona urbanas têm como 
função de servir de corredores ecológicos as espécies de fauna que estão relacionadas ao complemento de fonte de alimentos as espécies típicas das matas nativas. Essas espécies típicas das matas nativas são espécies circundantes aos centros urbanos (BRUN et al., 2007). As plantas invasoras transformam a estrutura e a composição de um ecossistema o que levar a exclusão ou repressão das nativas (MACK; OCCHIPINTI, 1999). Algumas cidades apresentaram maior variedade de espécies exóticas do que nativas, é o caso do município de Assis, onde foram encontrados 1915 indivíduos arbóreos, pertencentes a 54 espécies; em número de espécies, as plantas exóticas são mais predominantes na arborização da cidade com 31 espécies representando $61,82 \%$ do total (ROSSATTO; TSUBOY; FREI, 2008);em Alta Floresta, Carlinda e Nova Monte Verde foi levantado um total de 663 indivíduos, distribuídos em 20 famílias botânicas, 30 gêneros e 31 espécies. 51,6\% das espécies são exóticas à flora brasileira e 48,4\% são nativas (ALMEIDA; RONDON NETO, 2010(2)) e em Colíder e Matupá, cidades da região Norte do Estado de Mato Grosso, foram levantados 547 indivíduos, distribuídos em 15 famílias botânicas,21 gêneros e 21 espécies; 66,7\% das espécies são exóticas à flora brasileira e 33,3\%, nativas(ALMEIDA; RONDON NETO, 2010(1)). Essas alterações das paisagens vegetais comprometem o ambiente natural que podem tornar impróprio para abrigar determinadas aves que, exigem condições mais especificas para sua sobrevivência.

\section{OBJETIVOS}

Identificar e quantificar as espécies exóticas existentes nas vias públicas do município de Rancharia - SP.

\section{METODOLOGIA}

O estudo foi realizado no município de Rancharia, localizada no Sudoeste do Estado de São Paulo, distante 520 km capital. Seu território de 1.616,0 Km² e área urbana de $10,9 \mathrm{Km}^{2}$. Na área do município, predominam fisionomias vegetais típicas de dois biomas, Cerrado e Floresta Estacional Semidecidual. 


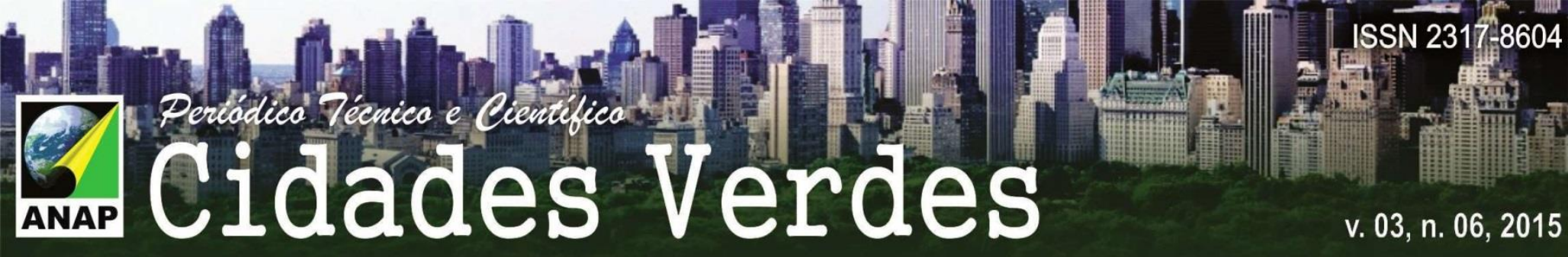

Foram levantados trinta e nove bairros, nos quais todos os indivíduos vegetais em vias públicas foram catalogados. Foram analisados os seguintes parâmetros: origem (nativa e exótica). A identificação foi realizada de acordo com a bibliografia especializada (LORENZI, 2003; LORENZI, 2004; LORENZI, 2009).

\section{RESULTADOS E DISCUSSÃO}

Foram catalogados 10.406 indivíduos. Deste total, 242 estavam mortos e 180 não foram classificados. Portanto, foi possível analisar os parâmetros em 9.984 indivíduos que foram identificadas em 150 espécies de 113 gêneros pertencentes a 49 famílias botânicas, deste total 90 (60\%) são espécies exóticas e 60 (40\%) são espécies nativas. Fabaceae foi à família que apresentou maiores números de espécies; seguido de Mrytaceae; Aracacea e Bignoniaceae. Licania tomentosa, (Chrysobalanaceae) apresentou maior frequência de indivíduos. Em termos de proporção, $7.704(77,2 \%)$ são de indivíduos de espécies nativas do Brasil e 2.280 $(22,8 \%)$ são de indivíduos de espécies exóticas, não pertencente a flora brasileira.As plantas exóticas são muito utilizadas na arborização devido as suas exuberâncias de florescimentos (LORENZI et al., 2003).A espécies exótica de maior frequência encontrada em vias pública foi Murraya paniculata (Rutaceae), que constitui 16,6\% do total de indivíduos exóticos na arborização (Tabela 1).

\begin{tabular}{llcc}
\multicolumn{4}{l}{ Tabela 1 - Frequência e total das espécies exóticas encontradas na zona urbana } \\
\hline Nome comum & \multicolumn{1}{l}{ Nome científico } & TOTAL & (F - \%) \\
\hline Dama-da-noite & Murrayapaniculata(L.) Jacq. & 380 & $16,6 \%$ \\
Figueira-benjamina & FicusbenjaminaL. & 222 & $9,7 \%$ \\
Ipê-de-jardim & Tecomastans(L.) Juss. exKunth & 183 & $8,0 \%$ \\
Chapéu-de-sol & TerminaliacatappaL. & 118 & $5,2 \%$ \\
Palmeira-imperial & Roystoneaoleracea(Jacq.) O.F. Cook & 115 & $5,1 \%$ \\
Espirradeira & NeriumoleanderL. & 90 & $4,0 \%$ \\
Manga & Mangifera indica L. & 89 & $3,4 \%$ \\
Chapéu-de-napoleão & Thevetiathevetioides(Kunth) k. Schum & 74 & $3,3 \%$ \\
Eucalipto & EucalyptusSP & 52 & $2,3 \%$ \\
Outros & & 969 & $42,4 \%$ \\
\hline
\end{tabular}

Fonte; Autores. 
No entanto, a representatividade de espécies - sobretudo no que se refere à comparação entre nativas e exóticas - não é uma situação positiva, devido à alta frequência de uma única espécie: Licania tomentosa, situação semelhante a observada por Rossatto,Tsuboy e Frei, 2008, Almeida e Rondon Neto, 2010(1) e Almeida; Rondon Neto, 2010(2). Isso aponta um baixo índice de equitabilidade entre as espécies vegetais (LORENZI, 2003). Portando o ambiente urbano de Rancharia é simplificado. Essa simplificação certamente afeta as cadeias alimentares e interações plantas-insetos-aves (LIM E SODHI, 2004), para sanar o problema ascidades devem procurar a introdução de novas espécies arbustivas e arbóreas nativas da região na arborização viária (BORTOLETO, et al., 2007ALMEIDA; RONDON NETO, 2010(2)).

Estudos sobre arborização em zona urbana em outras cidades brasileiras vem demostrando o predomínio das espécies exóticas sobre as nativas (BOENI; SILVEIRA, 2011). Na Estância Turística de Águas de São Pedro a ocorrência das espécies exóticas foi de $61,3 \%$ e as nativas do Brasil somaram 38,6\%. No município de Rancharia falta a diversificação das espécies nativas, elas garantem alimento aos organismos da região que circundam a área urbana.A melhor estratégia para ter uma arborização urbana adequada é um planejamento municipal que estabelece regras, realizando acompanhamento e controle de maneira efetiva (DA SILVAFILHO, 2002). As escolhas das espécies são importantes dentro da zona urbana para não promover problemas relacionados á abundância com as espécies utilizadas (ZILLER, 2001).

\section{CONCLUSÃO}

A quantidade de espécies exóticas é superior ao de espécies nativas, mas a quantidade de indivíduos de espécies exóticas não supera a quantidade de indivíduos de espécies nativas, este fato, acaba não sendo positivo, pois a arborização do município é homogênea por ter uma frequência alta de uma única espécie nativa, a Licania tomentosa. 


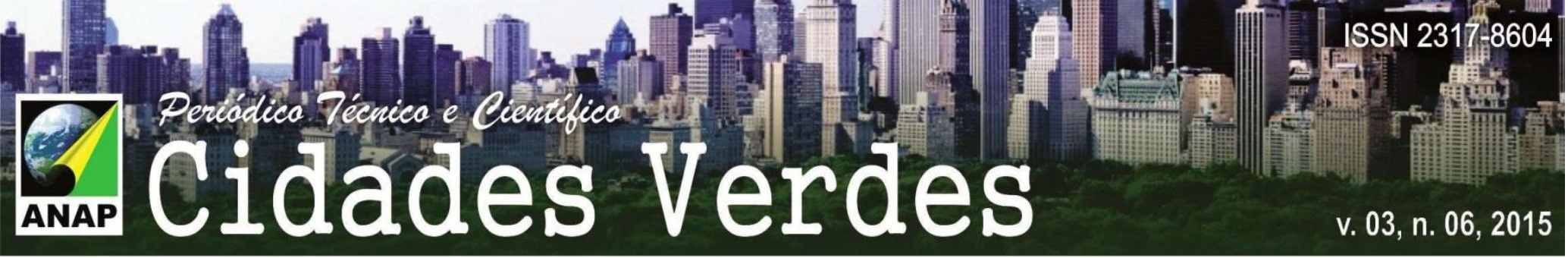

\section{REFERÊNCIAS}

ALMEIDA, D.N.; RONDON NETO, R.M.(1) Análise da arborização urbana de duas cidades da região norte do estado de Mato Grosso.Revista Árvore, Viçosa-MG. v.34, n.5, p.899-906, 2010.

ALMEIDA, D.N.; RONDON NETO, R.M.(2)Análise da arborização urbana de três cidades da região norte do Estado de Mato Grosso. Acta Amazônica, v. 40, n 4, p. 647-656, 2010.

ALVEY, A. A. Promoting and preserving biodiversity in the urban

forest. UrbanForestryandUrbanGreening, Gemany, v. 5, n. 4, p. 195-201, 2006.

ARGEL-DE-OLIVEIRA, M. M. Aves e vegetação em um bairro residencial da cidade de São Paulo (São Paulo, Brasil). Revista brasileira de zoologia, Curitiba, v. 12, n. 1, p. 81-92, 1995.

BLUM, C. T.; BORGO, M.; SAMPAIO, A. C. F. Espécies exóticas invasoras na arborização de vias públicas de Maringá-PR. Revista da Sociedade Brasileira de Arborização Urbana, Piracicaba, v. 3, n. 2, p. 78-97, 2008.

BOENI, B. O.; SILVEIRA, D. Diagnóstico da arborização urbana em bairro do município de Porto Alegre - RS, BRASIL. Revista da Sociedade Brasileira de Arborização Urbana, Piracicaba, v. 6, n.3, p. 189-206, 2011.

BORTOLETO, S.; DA SILVA-FILHO, D. F.; SOUZA, V. C.; FERREIRA, M. A. P.; POLIZEL, J. L.; RIBEIRO, R. C. S. Composição e distribuição da arborização viária da estância de Águas de São Pedro-SP. Revista da Sociedade Brasileira de ArborizaçãoUrbana, Piracicaba, v. 2, n. 3, p. 32-46, 2007.

DA SILVA FILHO, D. F. Cadastramento informatizado, sistematização e análise da arborização das vias públicas da área urbana do município de Jaboticabal, SP. 2002. 81 P. DISSERTAÇÃO (MESTRADO) - Faculdade de Ciências Agrárias e Veterinárias, Universidade Estadual Paulista "Júlio de Mesquita Filho", Jaboticabal.

LIM, H. C.; SODHI, N. S. Response's ofavian guilds to urbanization in a tropical city. Landscape and Urban Planning, Michigan, v. 66, n. 4, p. 199-215, 2004.

LORENZI, H. Árvores Brasileiras: manual de identificação e cultivo de planta arbórea nativas do Brasil. 3. ed. vol. 2. Nova Odessa: Instituto Plantarum, 2009.

LORENZI, H.; SOUZA, H. D.; COSTA, J. D. M.; CERQUEIRA, L. D.; FERREIRA, E. Palmeiras brasileiras e exóticas cultivadas. Nova Odessa: Instituto Plantarum de Estudos da Flora, 2004.

LORENZI, H.; SOUZA, H.; M; TORRES, M. A. V.; BACHER, L. B. Árvores exóticas no Brasil: ornamentais e aromáticas. Nova Odessa: Instituto Plantarum, 2003.

MACK, R. N.; OCCHIPINTI.Assessing the extent, status and dynamism of plant invasions: current and emerging approaches. In: Mooney, H. A. and Hobbs, H. A. Invasive species in a changing world, Washington D.C, p. 141-169, 1999.

ROSSATTO, D.R.; TSUBOY, M.S.F.; FREI,F. Arborização urbana na cidade de Assis-SP: uma abordagem quantitativa.Rev. SBAU, Piracicaba, v.3, n.3, p. 1-16, 2008. 
